in the first occipito-anterior position; the pelvis was roomy and the parts concerned in the passage of the child were soft and dilatable. There was evidently no obstacle to rapid delivery provided the uterine contractions were normal. The pains, however, continued to be very weak and irregular and had not the slightest effect in propelling the head into the pelvis. At night $30 \mathrm{gr}$. of chloral were given with the object of giving the patient some rest, there being no reason to hurry the labour either in the condition of the mother or that of the child, judging by the fotal heart sounds. The patient had four or five hours' sleep, and at 3 A.M. on the 27 th she was awakened by the pains recommencing. They continued up to noon, but although accompanied by a fair amount of pain they appeared to be quite useless owing to the irregular contraction of the uterus. As there was no obstacle except the charaoter of the pains to rapid delivery $2 \mathrm{dr}$. of the liquid extract of ergot were administered. About half an hour afterwards the pains became much stronger and more effectual, the head gradually progressing into the pelvis until at the level of the perineum, bat it then seemed to have little inclination to come any further. The forceps were therefore applied and the child, alive and healthy, was removed, so little resistance being offered that the child appeared rather to slip out than to be pulled out. The uterus after the birth of the child again dilated and could be felt through the abdominal wall in an elongated flabby condition; the hand was therefore introduced into the uterus and the placenta was removed without difficulty. The uterine cavity was syringed out with hot solution of 1 in 2000 perchloride of mercury and a hypodermic injection of ergotine was given. This caused the sluggish member to contract fairly firmly, very little blood being lost. The pulse, which at the time of delivery was 90 , quilckly dropped to 75 and the patient had no further trouble, convalescing in the usual way.

When we come to examine these cases we find that they agree only in one point-viz, the abnormally prolonged time of labour. They differ materially in the causes producing this result and in the effects on the patients. They illustrate very clearly the different effects on the mother of labour prolonged during the first stage, when the head is still above the pelvic brim, contrasted with that in which it is prolonged in the second stage, with the head tightly wedged in the pelvis and causing pressure on the maternal soft parts. In Cases 2 and 3 no ill effects were noticeable, although the membranes had broken twenty-four hours or more previously to delivery, but in Case 1 the result was fatal to both mother and child although, according to the midwife's statement, the head had not been lying in the pelvis for more than eight or ten hours. As regards the causes of the prolonged labours the three cases differed essentially from one another. In Case 1 matters probably went on fairly normally until the head reached the perineum, and then the patient becoming exhausted the propulsive force of the uterine contractions became proportionately weakened, with the result that no further progress was made. If at this time proper assistance had been given in the way of forceps there can be little doubt that the fatal result would have been aroided. Case 2 was clearly one in which no natural efforts would have brought about delivery owing to the abnormal size of the head, and the result obtained justified the extreme measure of destroying the child in order to save the mother. In Case 3 it is questionable how long labour would have been prolonged if it had been left to nature, owing to the want of proper uterine contractions, and it was, I think, one of those exceptional cases in which the administration of ergot during the first stage of labour was not only justifiable but very beneficial in rousing the sluggish uterus when after careful examination it was found that there was no obstruction to rapid delivery. In this important point this case differs fundamentally from Case 2, in which the administration of ergot would possibly have led to rupture of the uterus, or at any rate would have been a most dangerous and unscientific proceeding.

Capetown.

SWANSEA WATERWORKS.-At the meeting of the Swansea Town Council held on June 16th it was stated that with regard to the reservoir and tunnel the seal had been affixed to a contract for $£ 255,247$, so that the Cray Waterworks would now be shortly commenced.

\section{A PRELIMINARY NOTE ON THE}

\section{ACTION OF ROENTGEN RAYS UPON THE GROWTH AND ACTIVITY OF BACTERIA} AND MICRO-ORGANISMS. ${ }^{1}$

By R. NORRIS WOLFENDEN, M.D. CANTAB., AND

F. W. FORBES-ROSS, M.D. EDIN.

Some work has been done upon this subject, but as it has not led to any definite conclusions and in view of the some. what conflicting statements pablished we have thought that further investigations would be desirable. With this end in view we have selected the bacillus prodigiosus as the first subject for experiment. Six culture tubes of the normal growth on potato were obtained from University College laboratory and on May 25th these were set to incubate in as Hearson incubator at a temperature of $35^{\circ} \mathrm{C}$. in the dark. After five days' growth a tube was taken and from it two fresh cultures were made; one was a simple control culture and the other was rayed along with the mother culture for an hour. After twenty-four hours' growth that in the tubes which had been rayed (i.e., the mother and one of the daughter cultures) had increased markedly in comparison with the original tubes, which had now been growing for siz days. The control culture appeared to be only just showing a margin of increase. The difference in growth between the two tubes which had been rayed and the non-rayed control tube was very great, showing that undoubtedly the action of the $x$ ray tube had been exceedingly stimulative.

In order to determine whether the exposure of the potato. to prolonged $\mathrm{x}$ ray action would produce such changes in the medium of growth as to account for any marked increase of bacillary growth, two sterile tubes were rayed for one hour, a culture was then made on one of them from one of the previous tubes which had been rayed and which showed active growth, and another culture was made in the seconc tube from a culture which had never been rayed at all. These were incubated under precisely the same conditions as the previous tubes. When examined two days afterwards the growth in the rayed potato culture from rayed bacill had entirely outgrown the cultare on rayed potato from nonrayed bacilli, therefore the only canse of this exceptional growth must have been a property of the bacilli themselves and not of the medium of growth.

Cultures up to the fifth generation were made and the following facts were arrived at: $-A$ single exposure to the $x$ rays increased growth markedly and along with if there was an increase of chromogenetic property, even though grown in the warmth. As is well known the bacillus pro digiosus does not form pigment when grown in a warm atmosphere. Further exposure to the rays so stimulates the growth as to again deprive the bacilli of power to form this peculiar pigment in the warmth, though on retarn to cold this property is afterwards recovered to such an extent that the amount of pigmentation, though slightly different in colour, is in excess of the original culture. Up to the fiftb generation the result of exposure for an hour to $x$ rays of the culture is to produce an exuberant growth-apparently the pigment power is somewhat altered.

The method of application of the $x$ rays was as follows :With a large 18 in. spark coil of Newton's make a power was used of 16 volts, and from 8 to 10 ampères. The focus-tube was placed about 6 in. above the test-tube containing the potato growth. In every instance the exposure was of from fifty to sixty minutes' duration, with occasional resting of the tubes, which were run with the anodes as nearly red-hot as practicable.

We do not here attempt to enter into the explanation of these phenomena of growth. We are content to record the facts that exposure of the bacillus prodigiosus to the radia. tions of a focus tabe induces very marked increase of growth and peculiar changes in the pigment-forming powers of this particular micro-organism. We will merely add that in some of the lower forms of vegetable life the ame changes are observed, notably in the protococcus. An exposure of this organism to $\mathrm{x}$ rays for from five to ten minutes appears to $1 \mathrm{~A}$
1898. 
much stimulate its activity, and if the exposare is a little prolonged the cells become much paler, the chlorophyll disappears, and the protoplasmic contents are more granular. The cells recover their green colour when exposed to sunlight, but on renewed exposure to $\mathrm{x}$ rays the chlorophyll seems to disappear more or less completely.

The following microscopic changes are to be noticed as the result of exposure of these bacilli prodigiosi to $x$ radiations. There is apparently little to call for notice as regards the relative size of the rayed and non-rayed bacilli. As regards groupirg, an unusual property of the bacillus prodigiosus was apparent-that is, growth in chains or strepto-bacteria ; and further, what is at present giving rise to controversy, spore formation, which seems to be clearly established by the presence of a chain preparation. For the rest, the bacilli appear in both cases equally granular and stain equally at the ends and as irregularly.

We are continuing these experiments, especially upon the pathogenic bacilli, among which it is possible that changes in growth may be accompanied with some alterations in the character of the bacilli.

\section{Cirnical a dotes:}

\section{MEDICAL, SURGICAL, OBSTETRICAL, AND THERAPEUTICAL.}

\section{NOTES ON A CASE OF PUERPERAL ECLAMPSIA OCCURRING IN THE SIXTH MONTH OF PREGNANCY ; DEATH.}

BY H. Howakd Murphy, M.D. Cantab,

ZHONORARY MEDICAL OFFICER TO ST. JOHN'S HOSPITAL, TWICKENHAM.

THE following notes on the case of a patient who was seized with puerperal eclampsia in the sixth month may be of interest to readers of THE LANCET in general as well as to "R. C.," who recently asked for references to cases."

On Oct. 21st, 1897, I was asked in the morning to call on a patient, about thirty years of age, who had vomiting and cramps in the stomach. She had one child, an easy confinement, four years ago, and was now some five months pregnant. She had not felt very well for some days, her stomach seeming to be out of order. There was no history of colic or janndice previously or of any serious illness, the patient being generally healtby. The attack commenced after breakfast by some colicky pains aross the upper abdomen and pains across the loins. She had rolled on the floor with pain, felt faint, and vomited once. The bowels were last - opened on the 19th, when they acted well twice. I ordered an enema, a mixture with tincture of chloroform and morphia, fomentations, appropriate diet, \&c. In the afternoon there was another attack of the colicky pain and the patient vomited twice. The tongue was clean; the liver - dulness was not increased; there was tenderness in the region of the epigastrium, but not over the gall-bladder, which could not be felt. The pulse was 75 and good and the temperature was normal. During the evening a second - enema had cansed a free evacuation; but the colic had been very severe and she had vomited frequently and all she took. There were no uterine symptoms at all. Morphia $\frac{1}{4}$ gr.) was injected hypodermically. She slept for four hours quietly; then she awoke and had severe colic and frequent vomiting and about 3 A.M. there occurred severe convulsions which lasted for an hour. Her pulse was 80 and good. Another hypodermic injection of morphia quieted her. At 10 A.M. she had two convulsions; she kept fairly conscious between the attacks; she complained much of epigastric pain and threw herself about and vomited frequently. She had passed very little urine, which contained a cloud of albumin. At noon she was distinctly jaundiced and was becoming less conscious. The temperature had risen to $100^{\circ} \mathrm{F}$. and the pulse was 80 and of fair strength. Dr. Amand Routh kindly saw the patient on the afternoon of the 22nd in consultation. He considered that the eclamptic state demanded the induction of labour and Inding that the os was patulous he was soon able to pass in

1 The LANCET, May 21st, 1898. a finger, to rupture the membranes, and to bring down a leg. There were no uterine contractions. He advised the continuance of the morphia and the administration of nutrient enemata with some bromide and chloral. In three hours the uterus was emptied and washed out. There were no more convulsions ; the patient was quieter, but she also gradually became less capable of being roused to answer questions or to take food. On the $23 \mathrm{rd}$ she had a quiet night, without convulsion, vomiting, or complaints of pain. She had not required any morphia. She recognised and spoke to me, answering questions. She passed no urine and no action - of the bowels rook place. The pulse was 100 and weaker. She took food well. All day she lay very quietly and in much the same condition. As no urine was passed by the evening the catheter was nsed and yielded $16 \mathrm{oz}$ of urine which was very dark coloured with bile and contained much albumin. The liver was terder and the area of dulness was diminished. The tongue was coated. The pulse went up to 120 and got weaker. She was very jaundiced. On the 24th the patient had passed a very quiet night. She took liquid nourishment well. No urine was passed. The bowels were frequently opened with small liquid motions. She had no convulsions and did not vomit. There was loss of vision and she said she could not see me but she recognised my voice; she was rambling and semiconscious. The pulse was 120 and very weak and the temperature was $100^{\circ}$. In the afternoon the catheter drew off $1 \frac{1}{2} \mathrm{oz}$. of urine which was very dark with bile and contained some blood. About 4 P.M. she became quite unconscious and very weak and died quietly in half an hour. No post-mortem examination was held.

Dr. Routh agreed with me that there was acute atrophy of the liver in this case as well as the eclampsia. The latter ceased as soon as the uterus was emptied, as did the epigastric pain and romiting. The urine contained albumin, was scanty, and almost suppressed at last.

Twickenham.

\section{A CASE OF CONCEALMENT OF BIRTH.}

By Sanderson Møllok, L.R.C.P., L.R.C.S. Edin, L IF.P.S. GLASG.

THE following is a curious and interesting case as showing what can be done by one who has just given birth to a child.

A single woman, aged twenty-three Jears, lived with her father (who is a widower) and a sister, aged fifteen years. The mother died some years ago and the home surroundings and comforts of these two daughters had not been of the happiest. The elder sister, whose extraordinary conduct I am referring to, gave birth to a child about two years ago and I understand she was on that occasion attended by a midwife. She expected her second confinement last February. For some reason-most probably shame-she never mentioned her condition to anyone and for a month or six weeks before the event she kept to the house and was never seen outside, not even by the next door neighbours. At 12.30 P.M. on the day on which she was confined she told her sister that she was in pain and asked her to fetch her married sister who lived two and a half miles away. This sister was, however, unable to go as her children were all ill and she could not leave them. The young girl then ran nearly two miles for another sister, with the result that the second sister went at once. She arrived at her father's cottage at $330 \mathrm{P} . \mathrm{M}$. and finding the back door locked she ran round to the front and there met the girl who had just been confined. She then told her sister that she had had a "loss" and that she had put it in the water-closet. The girl was immediately put to bed and a neighbour was called and a close inspection of the water-closet revealed nothing which threw any light on this mysterious affair. The floor near the bed, the bedclothes, and the girl's linen were all soaked in blood. In the centre of another room and on the floor was a dirty old bag which had been used for stopping up the chimney, and in this bag, in which there was a large quantity of horsehair, a fully developed after.birth was found. Up the chimney in the same room another dirty bag was discovered which contained the body of a fall-time child. The matter was placed in the hands of the police and I made a postmortem examination. The umbilical cord was one yard long and was coiled round the child's neck, and the cord 